Khazanah: Jurnal Studi Islam dan Humaniora

ISSN: 0215-837X (p); 2460-7606 (e), Vol. 16 (2), 2018, pp. 227-248

DOI: $10.18592 /$ khazanah.v16i2.2199

\title{
KEKERABATAN DAN INTERAKSI SIMBOLIK BIDAN KAMPUNG DENGAN URANG HALUS DALAM MASYARAKAT BANJAR
}

\author{
Arni \\ Universitas Islam Negeri Antasari Banjarmasin \\ arnidaily007@gmail.com
}

\begin{abstract}
This article is an important part of the exploration of the development of local treasures related to the beliefs and behavior of traditional village midwives towards supernatural beings. The midwives in East Banjarmasin have a belief that there are supernatural creatures called supernatural beings, besides genies and angels. Their relationship with this supernatural person is very close, because supernatural people are part of their kinship. This supernatural person is believed to have taught them to massage through dreams. This creature can become an animal. Unseen people are people or humans who are God-idolized, can the time in the womb disappear by itself, or after birth disappear. The behavior of traditional village midwives towards these occult people is that they always establish kinship, by giving offerings in the form of bitter coffee, sweet coffee, water, sticky rice, eggs, bananas, red and white porridge. In Islam it is not explicitly talked about this supernatural person, there are only supernatural beings (genies and angels). It could be that in Islam the occult is grouped into genie, because genie means hidden, and the occult is also hidden. But according to the author, if there is a magic person other than the genie, then there is an Al-Quran verse that supports implicitly, namely in the Surah An-Nâs verses 4-6. That is the whisper of evil hidden into the chest (heart), not ears, and which whispers it from the genie and human.
\end{abstract}

Keywords: Believes, Traditional Village Midwife, Supernatural

Abstrak: Artikel ini bertujuan untuk mengeksplorasi dan menggambarkan khazanah lokal yang berhubungan dengan kepercayaan serta perilaku bidan kampung terbadap makbluk supernatural. Menggunakan metode penelitian studi kasus dengan teknik pengumpulan data wawancara dan observasi, peneliti mendeskripsikan pendapat dan persepsi Bidan Kampung di Kota Banjarmasin yang memiliki kepercayaan adanya makbluk supernatural yang disebut orang gaib, selain jin dan malaikat. Dari hasil penelitian diketahui bahwa bubungan mereka dengan orang gaib ini sangat dekat, karena orang gaib bagian dari kekerabatan mereka. 
Orang gaib inilah yang diyakini telah mengajari mereka memijat melalui mimpi. Makhluk ini bisa menjelma menjadi binatang. Orang gaib menurut pemahaman luas berupa orang atau manusia yang digaibkan Allah, bisa waktu dalam kandungan hilang dengan sendirinya, atau setelab labir menghilang. Perilaku bidan kampung terhadap orang gaib diketabui selalu menjalin bubungan kekerabatan, dengan cara memberi sesajen berupa kopi pahit, kopi manis, air putih, nasi ketan, telor, pisang, bubur merah dan putih. Dalam Islam tidak secara tegas dibicarakan tentang orang gaib ini, yang ada hanya makbluk gaib (jin dan malaikat). Bisa saja dalam Islam orang gaib itu dikelompokkan kepada jin, sebab jin artinya tersembunyi, dan orang gaib itu juga tersembunyi adanya. Namun menurut penulis, apabila orang gaib itu benar ada selain jin, maka ada saja ayat Al-Quran yang mendukung secara tersirat, yaitu pada surab An-Nâs ayat 4-6. Yaitu bisikan kejahatan tersembunyi ke dalam dada (hati), bukan ke telinga, dan yang membisikan itu dari golongan jin dan manusia.

Kata kunci: Kepercayaan, Bidan Kampung, Supernatural

\section{Pendahuluan}

Allah menciptakan makhluk yang esensial hanya 3 macam yakni manusia, jin dan malaikat. Malaikat diciptakan Allah dari cahaya terdapat dalam hadis, sedangkan manusia diciptakan dari tanah dan jin diciptakan berasal dari api (QS, ar-Rahman : 15) dan juga terdapat Hadis. Muslim dan Ahmad meriwayatkan dari Aisyah ra. Ia berkata Rasulullah bersabda:.

"Malaikat diciptakan dari cahaya, jin diciptakan dari api yang menyala, dan Adam diciptakan dari apa yang telah dijelaskan-Nya kepada kalian",

Makhluk supernatural yang ada dibicarakan dalam Islam hanya malaikat dan jin. Sedangkan iblis dari golongan jin, (QS, al-Kahfi: 50). Iblis ini adalah sangat jahat, dia menjerumuskan manusia ke neraka, menjauhkan manusia dari kebaikan sehingga dia disebut setan. Setan adalah sifat jahat dari jin ataupun manusia. Jadi istilah setan bisa dari golongan jin dan bisa juga manusia yang sangat jahat, (QS: surah alAn’am:112). Namun dalam fenomena kehidupan, seolah-oleh ada "pemain" tambahan dalam kehidupan dunia ini yakni ada yang dinamakan orang gaib. Sehingga seolah-olah makhluk supernatural (gaib) itu ada jin, malaikat, setan dan iblis, serta orang gaib. Jadi siapakah

${ }^{1}$ Wahid Abdus Salam Bali and Aunur Rafiq Shaleh Tamhid, Kesurupan jin dan cara pengobatannya secara Islam (Jakarta: Robbani Press, 1999), 31. 
"pemain " tambahan itu? selain malaikat dan jin tersebut, apakah memang orang gaib itu makhluk gaib yang esensial lain selain malaikat dan jin yang Allah ciptakan? Kepercayaan terhadap makhluk supernatural ini dalam antropologi disebut animisme, dan mereka yang meyakini makhluk gaib itu bisa berwujud binatang, maka ini dinamakan totemisme.

Hasil penelitian awal diketahui sebagian masyarakat Banjar beranggapan orang gaib adalah orang/manusia yang digaibkan Allah, bisa waktu dalam kandungan menghilang, atau setelah lahir. Manusia tidak melahirkan jin, sebab lain jenisnya. Sebagian masyarakat Banjar percaya bahwa orang gaib inilah yang membantu bidan kampung, dan ada juga anggapan sahabat empat (uriyah, tambuniyah, tubaniyah dan camariyah). Semua bidan kampung, mengaku bahwa memijat merupakan keahlian yang diperoleh dari hasil turunan nenek moyang, dan memperoleh keahliannya itu melalui mimpi.

Dari latar belakang inilah membuat penulis tertarik untuk meneliti lebih mendalam tentang, kepercayaan, dan perilaku bidan kampung di kota Banjarmasin Timur, terhadap orang gaib atau makhluk supernatural yang membantunya dalam praktik pijat. Peneliti tertarik untuk mengetahui bagaimana pandangan atau kepercayaan bidan kampung atau tukang pijat di Kota Banjarmasin terhadap orang gaib atau makhluk supernatural, dan bagaimana perilaku bidan kampung atau tukang pijat terhadap orang gaib atau makhluk supernatural tersebut. Oleh karenanya, artikel ini bertujuan untuk mengetahui kepercayaan serta perilaku bidan kampung di Kota Banjarmasin terhadap orang gaib atau makhluk supernatural. Artikel ini diharapkan memberikan kontribusi yang berharga dalam rangka memperluas wawasan, informasi dan pengetahuan terhadap kepercayaan dan perilaku sebagian masyarakat Banjar mengenai makhluk supernatural.

\section{Metode Pembahasan}

Jenis dan lokasi Penelitian: Penelitian ini adalah penelitian lapangan (studi kasus) yang berlokasi di Kota Banjarmasin. Teknik pengumpulan data yang digunakan adalah wawancara dan observasi untuk menggali data yang berkaitan dengan pandangan atau kepercayaan bidan kampung atau tukang pijat di Kecamatan Banjarmasin Timur, 
terhadap orang gaib atau makhluk supernatural, dan bagaimana perilaku bidan kampung atau tukang pijat terhadap orang gaib atau makhluk supernatural. Analisis data, yakni dengan pendekatan scientific-cumdoctrinier, yakni perpaduan antara metode ilmiah dengan perspektif agama Islam.

\section{Makhluk Supernatural dalam Perspektif Islam}

Salah satu pokok akidah Islam adalah beriman (meyakini) adanya hal-hal gaib. Menurut Abdullah bin Mas'ud, pengertian "gaib" adalah sesuatu yang tidak bisa kita indera, dan Allah serta rasul-Nya telah memberi tahu perkara gaib ini kepada kita. ${ }^{2}$ Dalam agama Islam makhluk supernatural hanya jin dan malaikat.

1. Jin.

Jin secara bahasa berarti tersembunyi, sebab mereka hidup dalam kondisi tersebut. Alam jin adalah alam tidak kasatmata, berbeda dengan alam manusia yang tampak dan jelas. Kata “ jin” bentuknya plural (jama) sedangkan bentuk tunggalnya (mufrad) adalah "jinni".3 Adapun definisi lain tentang jin yaitu, jin adalah suatu makhluk yang tak dapat dipandang oleh manusia (QS, al-A'raaf: 27). Jin ini banyak terdapat di tempattempat yang kotor dan najis seperti, tempat buang kotoran, pemandian, sampah-sampah, kuburan, pasar juga bisa tinggal bersama manusia di rumah- rumah dll. ${ }^{4}$

Mereka ada yang muslim dan ada pula yang kafir, (QS, Jin/72: 11). Manusia bisa bekerjasama dengan jin. Walaupun demikian karena kita tidak tahu agama mereka, maka dilarang minta bantuannya sebab akan menambah dosa dan kesalahan saja (QS, Jin: 6). Al-Asyqar berkata: "Bisa jadi seorang muslim mampu mempengaruhi jin pendamping (qarin), kemudian jin itu masuk Islam”. Ahmad dan Muslim telah

\footnotetext{
${ }^{2}$ Wahid Abdussalam Bali and Sarwedi Hasibuan, Ruqyah (Solo, Indonesia: PT Aqwam Media Profetika, 2011), 21.

${ }^{3}$ Ibrahim Kamal Adham, Kupas tuntas masalah jin dan sibir (Jakarta: Darus Sunnah, 2009), 72.

${ }^{4}$ Umar Sulaiman Al-Asyqar, Alam Makbluk Supernatural, (Jakarta: CV. Firdaus, 1992), 34 .
} 
meriwayatkan dari Ibnu Mas'ud, ia berkata telah bersabda Rasulullah saw:

Setiap orang dari kalian punya pendamping dari jin dan pendamping dari malaikat. Para sahabat bertanya: "Termasuk engkau wahai Rasulallah:? Nabi saw menjawab: "Termasuk aku", tetapi Allah telah membantuku menundukeannya, kemudian dia masuk Islam, sehingga tidak memerintabkan aku kecuali dengan kebaikan."5

Manusia bisa saja kawin dengan jin. As-Suyuthi telah menyebutkan riwayat-riwayat dan kabar dari orang-orang salaf dan ulamanya yang menunjukkan terjadi perkawinan manusia dengan jin. Ibnu Taimiyah mengatakan kadang-kadang manusia kawin dengan jin dan melahirkan seorang anak dari keduanya. ${ }^{6}$

2. Malaikat

Mempercayai adanya malaikat adalah salah satu rukun iman. Malaikat ini diciptakan Allah dari Cahaya. Oleh karena itu malaikat adalah makhluk halus yang tidak dapat dilihat dengan panca indera. Mempercayai atau beriman kepada malaikat termasuk mempercayai hal yang gaib. Malaikat memiliki sifat mulia, dan memiliki tugas, di antaranya mendamping manusia hidup hingga meninggal dunia. ${ }^{7}$ Dan dapat membantu manusia dalam hal kebaikan misalnya dalam perang Badr melawan orang kafir Quraisy (QS: Ali Imran: 124 -125).

\section{Makhluk Supernatural dalam Kajian Agama}

1. Animisme

Kata Animisme berasal dari kata "anima", dari bahasa Latin “animus", bahasa Yunani “apepus”, dalam bahasa Sansekerta disebut "prana", dan dalam bahasa Ibrani disebut "ruab" yang berarti nafas atau jiwa. ${ }^{8}$ Animisme adalah suatu kepercayaan terhadap makhluk halus dan roh, serta keyakinan seperti ini sudah banyak dianut oleh bangsa-bangsa yang belum bersentuhan ataupun belum pernah menerima ajaran yang

\footnotetext{
${ }^{5}$ Bali and Tamhid, Kesurupan jin dan cara pengobatannya secara Islam, 60.

${ }^{6}$ Umar Sulaiman Al-Asyqar, 13.

${ }^{7}$ Rahmat Hidayat, Kekerabatan Dengan Makbluk Astral (Banjarmasin: IAIN Antasari Press, 2014), 16.

${ }^{8}$ Zakiah Daradjat, Perbandingan Agama I (Jakarta: Bumi Aksara, 1996), 25.
} 
berdasarkan daripada agama samawi (wahyu). ${ }^{9}$ Menurut pandangan animisme, dunia penuh dengan makhluk halus yang mendiami tempat seperti rumah, kebun, ladang, desa, air, gunung, pohon, batu, dan sebagainya. Makhluk halus ini bisa mengganggu, mencelakakan manusia, oleh karena itu orang primitif dalam hubungan dengan makhluk halus itu bersikap hati-hati. Makhluk halus dalam tindakannya selalu menakjubkan dan dapat mengatasi segala tindakan manusia. ${ }^{10}$ Makhluk halus punya kekuatan dan kehendak, bisa merasa senang dan marah. Oleh karena itu keridaannya harus dicari, diusahakan agar ia jangan marah dengan memberi makan, memberi korban kepadanya dan mengadakan upacara khusus untuknya. ${ }^{11}$

\section{Totemisme}

Totemisme merupakan fenomena yang menunjukkan kepada hubungan organisasional khusus antara suatu suku bangsa dan suatu spesies tertentu dalam wilayah binatang atau tumbuhan. Dan hubungan ini diungkapkan sebagian dalam upacara-upacara khusus. Para penganut kepercayaan totemisme meyakini bahwa mereka diturunkan dari satu leluhur totem yang mistis, atau bahwa mereka dan para anggota dari totem sejenis merupakan "saudara". Mereka menggunakan totem sebagai simbol kelompok dan menganggapnya sebagai "pelindung" kelompok secara keseluruhan. Masalah pokok dalam totemisme ialah adanya persekutuan, partisipasi dan saling menjadi bagian antara manusia dan binatang. $^{12}$ Dan manusia dapat memperoleh keselamatan dari perhubungannya dengan binatang. Hubungan kekerabatan dan kekeluargaan dengan binatang seperti buaya, merupakan paham totemisme, yang memperlihatkan adanya sikap-sikap khusus terhadap binatang tersebut seperti sikap kagum, tertarik, dan rasa takut serta cemas, karena binatang itu diakui memiliki hubungan yang erat dengan

${ }^{9}$ Ridwan Hasan, "Kepercayaan Animisme Dan Dinamisme Dalam Masyarakat Islam Aceh," MIQOT: Jurnal Ilmu-Ilmu Keislaman 36, no. 2 (December 2, 2012), https://doi.org/10.30821/miqot.v36i2.119.

${ }^{10}$ Ayatullah Humaeni, "Makna Kultural Mitos Dalam Budaya Masyarakat Banten," Antropologi Indonesia, December 18, 2013, https://doi.org/10.7454/ai.v33i3.2461.

${ }^{11}$ Harun Nasution, Islam ditinjau dari berbagai aspeknya (Jakarta: Penerbit Universitas Indonesia, 1984).

${ }^{12}$ Maghfur Ahmad, "Agama dan Psikoanalisa Sigmund Freud," RELIGLA, October 3, 2017, https://doi.org/10.28918/religia.v14i2.92. 


\section{Kekerabatan dan Interaksi Simbolik Bidan Kampung dengan Urang Halus dalam Masyarakat Banjar}

kehidupan manusia. Malah sering meningkat kepada pengakuan bahwa binatang tersebut nenek moyang atau leluhurnya.

Totem bukanlah fenomena khusus di suatu tempat. Ini tidak terbatas pada masyarakat suku Aborigin di mana Emile Durkheim melakukan penelitiannya. Namun juga berada di banyak tempat lain. Di kalangan masyarakat Melanesia dikenal mana yang secara konseptual sama dengan totem. Di dalam masyarakat Indian Amerika juga dikenal istilah yang serupa dengan totem yaitu wakan, manitou, dan orenda. Dalam masyarakat Jawa, konsep serupa lebih lazim dikenal sebagai danyang. ${ }^{13}$

Taylor mengutip dari Wilken tentang masalah buaya-buaya yang dianggap baik dan bersahabat dengan manusia yang baik, dan menjadi pelindung mereka. Buaya-buaya ini dapat membunuh siapa saja yang dianggap sebagai musuhnya. Persembahan korban selalu dilakukan terhadap buaya itu dan orang berusaha mencari berkah. ${ }^{14}$

\section{Kepercayaan dan Perilaku Bidan Kampung terhadap Makhluk Supernatural (Orang Gaib)}

\section{Kasus I (Jubaidah)}

Jubaidah mengakui sudah tujuh tahun lamanya melakukan praktik pijat. Keahlian ini diperoleh bukan hasil belajar, melainkan awalnya ini didapat melalui mimpi, meluruskan benang yang kusut serta memijat orang putih. Dan keahliannya merupakan turunan dari datuk yang pekerjaannya sehari-hari tukang pijat. Datuknya telah bersahabat dengan tiga orang gaib dalam bentuk buaya jelmaan yang bernama Datu Abi, Datu Kartamina dan Datu Azam. Ketiga orang gaib ini membantunya dalam melakukan pemijatan, ditambah lagi ada bantuan dari anaknya (Istiqamah) yang hilang sejak dalam kandungan. Istiqamah ini sering menampakkan wujudnya dalam bentuk ular. Istiqamah ini

${ }^{13}$ Muh Syamsuddin, "Totemisme Dan Pergeserannya: Studi Terhadap Tradisi Lokal Di Sendang Mandong, Klaten, Jawa Tengah," RELIGI JURNAL STUDI $A G A M A-A G A M A$ 13 ,

no.

01

(2017):

100 , https://doi.org/10.14421/rejusta.2017.1302-06.

${ }^{14}$ Arni, "Kepercayaan Dan Perlakuan Masyarakat Banjar Terhadap Jimat-Jimat Penolak Penyakit," Jurnal Studia Insania 4, no. 1 (2016): 39-56. 
saudara kembar dengan anaknya yang pertama yaitu Misrawati. Pada mulanya dia tidak tahu kalau akan menjadi bidan kampung atau tukang pijat. Keadaan ini baru disadarinya tangannya sakit, yang tidak tersembuhkan secara medis. Kemudian menemui Harmain tukang pijat di Sungai Turak, sambil memijatnya Harmain mengatakan : "tanganmu harus urutakan ka orang lain, ikam ini menuruti tangan Julak (datu Jubaidab) yang pekerjaannya sebagai tukang pijat, kamu akan jadi bidan atau tukang pijat nanti”. Harmain mengharap agar Jubaidah bisa menerima amanah sebagai tukang pijat, dan bantulah orang yang minta tolong. Waktu Jubaidah tinggal di Berau ada anak orang Dayak sedang sakit yang tinggal di samping rumahnya, setelah dibantunya memijat ternyata sembuh. Dari sini diketahuinya ada keahlian memijat pada dirinya. Jubaidah menuturkan bahwa dia punya anak sebelas orang. Anaknya yang telah menghilang (Istiqamah) sering merasuk ke dalam tubuh saudarinya yaitu Misrawati, Masliannor dan Migawati, dalam bentuk ular dan selalu membantu saudarinya atau ibunya bila ada orang niat jahat kepada keluarganya, dengan cara memberi bisikan kepadanya.

Jubaidah dalam membantu orang yang hamil tua, agar mudah dalam melahirkan, dengan cara memberi air yang di beri mantra. Adapun mantra untuk ibu hamil agar mudah melahirkan adalah:

"Bismillabirrahmanirrahim, hanyut tampang keladi bilang. Hanyut maulak di Murung Sari Balari ikam putri tanggirang, lulus sarta uri tambuni.

Kemudian baca surah al-Kautsar tujuh kali.

Keahlian sebagai bidan kampung atau tukang pijat, juga selalu dibantu oleh saudara empat yaitu: uriyah, tambuniyah, camariyah dan tubaniyah. Keluarganya yang gaib dapat membantunya, seperti yang dilakukan Jubaidah ketika anaknya yang bernama Saidah dihina, dilecehkan oleh seorang lelaki, yang mengatakan Saidah hitam, jelek siapa yang mau dengannya. Mendengar penghinaan ini Jubaidah sebagai orang tua sangat tersinggung. Dia minta bantuan kepada keluarga gaibnya sambil membaca mantra:

Bismillahirrahmanirrabim.

Hai (Sebut namanya...) 


\section{Kekerabatan dan Interaksi Simbolik Bidan Kampung dengan Urang Halus dalam Masyarakat Banjar}

Inya guring minta bangunakan. Inya bangun minta dudukakan. Inya duduk minta diriyakan. Inya badiri minta jalanakan. Minta sampaiyakan ka rumah tangga ini. Satikar sabantal lawan aku. Barkat la ilaba illa mubammadur rasulullah.

Setelah dibacanya mantra itu, keesokan harinya datanglah lelaki yang menghina anaknya itu, untuk minta minta maaf sekaligus menyatakan cintanya kepada anaknya, hingga terkawin sampai sekarang berumah tangga. Perilakunya menjalin hubungan dengan orang gaib, baik dengan orang gaib sahabat datuknya atau anaknya yang gaib, dia selalu menyediakan kopi pahit, kopi manis serta nasi ketan, telor dan pisang mahuli, yang diletakan di meja dalam rumahnya pada waktu tertentu. ${ }^{15}$

\section{Kasus II ( Kartini)}

Kartini menuturkan bahwa kurang lebih sepuluh tahun yang lalu, dia sudah menekuni profesinya sebagai bidan. Keahlian memijat bukan didapat dari belajar atau berguru kepada orang lain, melainkan diperoleh dari hasil turunan. Dikatakannya bahwa kakeknya yang bernama Thahir dan dipanggil masyarakat dengan panggilan Mbah Thahir atau Yayi Thahir. Dia bukan hanya ahli memijat, tetapi juga pandai menangani ibuibu yang mau melahirkan, walaupun dia seorang laki-laki. Orang-orang yang dibantunya, bukan manusia saja, namun pernah juga membantu orang gaib yang mau melahirkan. Suami orang gaib itu datang minta tolong kepada Mbah Thahir agar menolong isterinya yang mau melahirkan di tempatnya atau di alam gaib. Setelah dibantunya, lahirlah anaknya yang berbulu hitam badannya sebagaimana ayah dan ibunya. Ketika Mbah Thahir mau pulang, oleh orang gaib diantar ke alam nyata serta dikasihnya daging dan uang. Anehnya sampai di rumah ternyata daging itu berubah menjadi potongan-potongan kayu dan uang menjadi daundaun.

Orang gaib itu katanya sebagaimana kita, mereka juga punya tempat tinggal, jalan, kendaraan, pekerjaan, kawin mengawini dan beranak pinak dan sebagainya. Manusia yang dapat memasuki alam gaib ini, akan menyaksikan keindahan rumah-rumah, jalan, bangunan-

${ }^{15}$ Jubaidah, Bidan Kampung/Tukang Pijat, Wawancara Pribadi, Banjarmasin Timur 21 Oktober 2017. 
bangunan gedung, tapi bila sudah ke luar atau sudah berada di alam nyata, dan bila melihat ke belakang, bisa saja rumah yang dilihat indah seperti gedung, ketika di alam gaib, ternyata hanya sebuah pohon besar yang rindang. Pesan Mbah Thahir kepada Kartini, kita harus menolong orang yang minta tolong, walaupun dia orang gaib, tetap kita tolong. Sebab mereka makhluk Allah juga.

Pada suatu hari Mbah Thahir (kakek Kartini) mengatakan kepada anaknya (Mursinah), nanti kamu akan jadi bidan/tukang pijat, meneruskan pekerjaanku ini, tapi Mursinah (ibu Kartini) langsung menolaknya. Kalau kamu tidak bersedia, kata Mbah Thahir biar anakmu (cucuku Kartini) nanti yang menggantikannya, dan saat itu Kartini masih Sekolah Dasar (SD). Lebih jauh Kartini menerangkan bahwa ibunya yang bernama Mursinah walau tidak bersedia menjadi bidan, tetapi dia sering menolong orang gaib, yakni memeliharakan, menjagakan anak orang gaib itu dalam buayan di sebuah rumah ketika orang tuanya pergi. Dia dapat melihat atau menyaksikan sendiri kehidupan orang-orang gaib itu. Pekerjaan ini sering terjadi. Mursinah mengaku mendengar saja suarasuara dari keluarga di rumahnya di alam nyata seperti suara suami, dan anak-anak, "kenapa ibu tidak pulang padahal sudah senja menjelang magrib". Mursinah mengaku mendengar, namun tidak bisa menjawab karena berada di alam sebelah atau alam gaib. Tetapi ketika dia pulang ke alam nyata, dilihatnya ke belakang ternyata rumah tepat anak orang gaib dalam buayan itu hanya sebuah pohon besar di hutan. Karena orang tua Kartini ini dapat berhubungan langsung dengan orang gaib sehingga dia selalu memberi sesajen kepadanya, berupa kopi pahit dan kopi manis, serta nasi ketan yang dilengkapi dengan telor dan pisang dan kelapa yang diberi gula merah.

Kartini waktu muda (masih perawan) menyadari dia nanti akan menjadi bidan, setelah berulang kali mimpi memijat orang putih dan juga diberi tahu oleh kakek dan ibunya serta juga diberi tahu oleh seorang janda yang minta pijat kepadanya. Pada suatu hari si janda itu memegang tangan Kartini dan langsung mengatakan kamu bila sudah tua nanti akan menjadi tukang pijat. Namun ternyata perkataan si Janda itu terbukti setelah Kartini berumah tangga dan punya anak, sebab bila ada orang yang keseleo, atau sakit, yang datang kepadanya dan minta dipijatkan, maka orang yang dipijat itu selalu mengatakan rasa sembuh dari sakit. Mulai saat itu sekitar tahun 2007 pekerjaan sebagai bidan/tukang pijat 


\section{Kekerabatan dan Interaksi Simbolik Bidan Kampung dengan Urang Halus dalam Masyarakat Banjar}

ditekuninya hingga sekarang. Dia selalu membantu orang yang minta pijat, baik perempuan atau lali-laki.

Walaupun Kartini tidak pernah melihat orang gaib yang membantunya, namun anaknya sering melihat orang gaib tersebut yang berupa manusia di rumahnya. Jadi orang gaib tersebut tetap dirasakan adanya, dan selalu berhubungan dengannya atau keluarganya. ${ }^{16}$

\section{Kasus III (Salamah)}

Salamah yang mempunyai dua anak, yang bernama Marlina dan Liana, mengaku mengetahui bakal menjadi bidan/tukang pijat sejak masih remaja. Pada suatu malam ia bermimpi meluruskan benang yang kusut, dan mimpi itu berulang kali terjadi pada beberapa malam. Kejadian ini diceritakan kepada ibunya yang bernama Mastan, yang pekerjaannya bidan/ tukang pijat. Profesi ibunya ini merupakan warisan dari keahlian datunya, juriat daerah Taniran di Kandangan (HSS), yang juga tukang pijat patah tulang, kaseleo dll. Orang tua Salamah (Mastan) mengatakan kepadanya, nanti kamu akan menjadi bidan/tukang pijat. Mendengar akan menjadi tukang pijat Salamah langsung menolak. Ibunya mengatakan ini sudah ada alamat atau tanda bahwa kelak kamu akan mengganti pekerjaanku, dan ini tidak bisa kau hindari, kalau dihindari akan timbul masalah yang sulit di atasi, lihat saja nanti tutur ibunya.

Ketika Salamah berumah tangga dan punya anak, dia bermimpi lagi memijat perempuan putih. Dalam mimpi itu dia dibantu ibu haji yaitu orang gaib yang berwujud manusia, dan mengatakan kepada Salamah bagian depan atau dekat keluarnya bayi kamu yang menjaga dan aku atas perut mendorong, dan bila kepala bayi sudah mau keluar, tariklah telinganya, maka bayi akan cepat keluar/lahir. Ketika dilihatnya kepala bayi mulai keluar maka tangan Salamah bergerak menyentuh telinga bayi, namun seketika itu juga dia terbangun dari tidurnya.

Tidak berapa lama dari kejadian itu tangan kanannya sakit, dan di bawa berobat ke dokter Haitami. Namun, setelah diperiksa dokter, ternyata penyakitnya tidak ditemukan. Dan pada suatu hari teman Salamah membawanya berobat kepada Ni Aluh di Teluk Tiram. Ni Aluh

${ }^{16}$ Kartini, Bidan Kampung/Tukang Pijat, Wawancara Pribadi, Banjarmasin Timur 28 Oktober 2017. 
mengatakan tidak ada penyakitnya. Ini hanya tanda kamu mewarisi keahlian ibumu sebagai bidan. Salamah langsung menolak. Kata Ni Aluh tidak akan bisa bila sudah sampai waktunya kamu harus menerimanya dengan ikhlas, tapi ini nanti setelah kamu tua. Kalau begitu kata Salamah tidak mengapa kalau saya sudah tua,

Keahlian memijat ini memang dipraktekannya setelah tua dan punya anak. Dan lebih jauh diterangkan Salamah bahwa keahliannya selama ini telah dibantu oleh orang halus yaitu saudari gaibnya yang bernama putri Mayang Sari, sebab waktu dia dilahirkan kembar dengan Mayang Sari yaitu saudarinya yang hilang (gaib). Hal ini dikatakan oleh bidan yang membantu kelahirannya di kampung Negara (HSS). Bidan ini mengharapkan agar anak yang hilang ini dipelihara baik-baik.

Oleh karena itu sampai sekarang perilaku Salamah terhadap saudarinya yang gaib dengan menyediakan ranjang kuning kecil, yang dilengkapi dengan tilam, bantal, guling dan kelambu kecil yang diletakkan di atas lemari dalam rumahnya. Salamah juga memberi minuman tiga gelas air, yaitu air kopi manis, kopi pahit dan air putih setiap malam Jumat yang diletakkan di atas meja dalam rumahnya, setelah itu dibacakan doa selamat, kemudian diminum kopinya. Selain itu setiap tiga bulan sekali memberi nasi kuning dan telor (nasi lamak), yang juga dibacakan doa selamat, kemudian dimakan bersama keluarga.

Pernah dia lupa menyediakan hidangan tersebut, akibatnya tangannya sakit. Salamah menemui orang pintar yang bernama Abdul Khair di Negara menanyakan tentang penyakitnya. Abdul Khair mengatakan Salamah lupa memberi hidangan untuk saudarinya, lalu dia pulang membuatkan hidangan untuk saudara gaibnya (putri Mayang Sari). Begitu disediakan hidangan, seketika itu sakitnya sembuh. Lebih jauh dia menjelaskan bahwa waktu dulu badannya tidak boleh karigatan (kotor), sebab kalau karigatan langsung seluruh tubuh alergi. Setiap masuk bawah rumah pasti seluruh tubuh kena penyakit alergi, padahal bawah rumahnya bersih. Maka untuk mengatasinya harus mandi kembang melati.

Salamah mengaku nenek moyangnya berasal dari keturunan Putri Junjung Buih di Candi Agung Amuntai. Putri Junjung Buih itu katanya orang gaib bukan jin, dia manusia yang digaibkan sebagimana saudarinya yang gaib yaitu yang bernama Putri Mayang Sari. 


\section{Kekerabatan dan Interaksi Simbolik Bidan Kampung dengan Urang Halus dalam Masyarakat Banjar}

Saudari gaib Salamah bernama Putri Mayang Sari ini sering menemuinya sejak kecil, selalu bermain dengannya dan setelah tua ini juga sering dia datang menemui dengan wajahnya yang cantik, kulitnya putih dan rambut hitan panjang bergelombang. Salamah tidak takut karena sudah terbiasa berjumpa dengan saudari gaibnya itu. Apalagi tahu bahwa Putri Mayang Sari yang selalu membantu pekerjaannya. ${ }^{17}$

\section{Kasus IV ( Hj. Mulyana)}

Mulyana menekuni pekerjaan sebagai bidan sejak tahun 2004, setelah datang berhaji, dan mengetahui bakal menjadi bidan sudah lama, sejak sebelum tahun 2000 M. Dia mengaku hampir selama tiga bulan setiap akan tidur selalu gelisah. Namun bila tertidur pasti bermimpi ditemui seorang laki-laki putih memakai jubah dan surban, dan terkadang berbicara kepada Mulyana “ikam manjadi paurutan” (kamu akan menjadi tukang pijat). Mulyana menjawab saya tidak bersedia. Laki-laki itu mengatakan lagi: "nanti kamu diajari ada ayatnya dalam Al-Qur'an dan akan kami bantu juga". Kejadian ini selalu berulang, lalu diceritakan kepada suaminya (Haryono). Suaminya tidak mengizinkan, kamu nanti akan kelelahan. Tidak lama setelah itu suaminya meninggal dunia pada tahun 2000. Pada tahun 2004 Mulyana menunaikan ibadah haji, atas anjuran keempat anaknya (Mahlian, Latifah, Nisa dan Agus).

Setelah pulang dari ibadah haji, dia bermimpi seorang laki-laki putih itu datang lagi membawa perempuan tanpa tangan dan kaki, dan perutnya sudah dibelah, sehingga seluruh isi perutnya terlihat. Laki-laki itu mengajari cara memijat. Pada siang harinya Hj. Mulyana tetap tidak bersedia menjadi tukang pijat. Setelah itu dia sakit pinggang, yang tidak dapat disembuhkan secara medis. Namun setelah disetujui sebagai bidan, maka seketika itu sembuhlah.

Pengalaman pertama $\mathrm{Hj}$. Mulyana memijat, suatu hari datang ke rumahnya orang yang tidak dikenal. Seorang isteri membawa suaminya sedang sakit perut. Isterinya yang mengendarai kendaraan motor, dan suaminya membonceng. Dia minta dipijat perutnya. Kata $\mathrm{Hj}$. Mulyana, aku tidak pandai memijat. Orang ini tetap mengharap agar dipijatkan.

${ }^{17}$ Salamah, Bidan Kampung/Tukang Pijat, Wawancara Pribadi, Banjarmasin Timur 11 November 2017. 
Karena dipaksa dan ada keinginan menolong, sehingga dipijatnya di bagian punggung menelusuri urat perut, kemudian ke bagian perut, keadaan ini dilakukan memang petunjuk dalam mimpinya, tidak boleh memijat langsung ke perut yang sakit. Setelah dipijatnya sembuh. Kedua orang itu mengucapkan terimakasih dan tidak terlihat lagi kemana pulangnya. Oleh karena itu dia beranggapan itu adalah orang gaib. Setelah kejadian itu, banyak orang yang datang untuk dipijatkan, dan $\mathrm{Hj}$. Mulyana akhirnya selalu menolong siapapun yang minta bantuannya. Hj. Mulyana menuturkan ilmu ini merupakan ilmu turunan, dia turunan ketiga setelah neneknya yang bernama Jahra kemudian kakaknya (Arbainah). Setelah Hj. Mulyana akan ada lagi mewarisi sebanyak empat orang, begitulah yang diceritakan lewat mimpi. ${ }^{18}$

\section{Kasus V ( Hamsiah)}

Hamsiah berusia 50 tahun, menerangkan bahwa telah melakukan praktik pijat sudah sebelas tahun lamanya. Sebelum pandai dalam memijat, diberi pirasat lewat mimpi meluruskan benang yang kusut dan sering mimpi berkelahi dengan orang hitam, dan dia selalu menang. Pernah juga katanya mimpi membantu orang yang mau melahirkan, dan diperlihatkan segala isi perutnya, serta diajari cara mengatasi segala persoalan yang berhubungan isi perut, baik masalah bayi dalam kandungan ataupun segala usus, urat, keadaan posisi bayi, dan lainnya.

Ketika sudah tahu bahwa dirinya akan menjadi bidan, dia menolak karena merasa malu. Pada suatu hari anaknya yang pertama jatuh dari meja, namun ternyata siku tangannya keseleo (terlepas sendinya). Kemudian dibawa ke beberapa tukang pijat, hasilnya malah semakin bertambah parah sakitnya. Pada suatu malam saat anaknya tidur, Hamsiah mencoba memijatnya sendiri, ternyata keesokan harinya anaknya sembuh dari sakit itu. Berawal dari situlah akhirnya banyak keluarga dan orang lain yang datang minta dipijatkan.

Hamsiah menyadari bahwa keahlian memijat yang dimilikinya merupakan keahlian dari hasil turunan, baik dari pihak ibu mau pun bapaknya ada yang pandai memijat. Dalam melakukan pemijatan dia mengaku bisa membedakan penyakit yang alami atau yang akibat gangguan jin seperti kapubunan, kapidaraan. Bila waktu memijat

${ }^{18} \mathrm{Hj}$. Mulyana, Bidan Kampung/Tukang Pijat, Wawancara Pribadi, Banjarmasin Timur 18 November 2017. 


\section{Kekerabatan dan Interaksi Simbolik Bidan Kampung dengan Urang Halus dalam Masyarakat Banjar}

seseorang, tiba-tiba kepalanya terasa sakit, maka ini menurutnya sebuah firasat bahwa orang yang dipijatnya itu dimasuki jin, dan orang tersebut dikatakan masyarakat kena kapubunan atau kapidaraan. Apabila orang yang dipijatnya banyak angin dalam tubuhnya, maka Hamsiah mengetahui hal itu dari sentuhan tangannya dan selalu keluar angin di mulutnya (mariga).

Perilakunya dalam rangka menjalin hubungan dengan makhluk supernatural yaitu orang gaib yang membantu dalam pemijatan, dia setiap tiga bulan membuat kue bubur puth dan bubur merah serta air kopi manis dan pahit yang diletakkan di sebuah ruang dalam rumahnya, kemudian dibacakan doa selamat, dan kue itu dimakan bersama keluarga. ${ }^{19}$

\section{Tinjauan tentang Kepercayaan dan Perilaku Bidan Kampung terhadap Orang Gaib}

Mencermati segala sesuatu yang berhubungan dengan bidan kampung atau tukang pijat di kota Banjarmasin Timur, sebagaimana dikemukakan di atas, tidak bisa dipungkiri bahwa adanya pengakuan hubungan antara bidan kampung dengan makhluk supernatural yakni orang gaib. Semua responden dari kelima kasus mempercayai, meyakini adanya orang gaib, dan mengakui menjalin hubungan kekerabatan dengan orang gaib tersebut, sekaligus juga mendapat bantuannya dalam menolong pasien.

\section{Pandangan, Kepercayaan Bidan Kampung/Tukang Pijat terhadap Orang Gaib.}

Memang orang Banjar sebagaimana dikemukakan oleh Alfani Daud dalam bukunya "Islam dan Masyarakat Banjar", pada umumnya mempercayai terhadap adanya orang gaib. Di antara tokoh-tokoh jenis makhluk halus ini yang terkemuka termasuk tokoh-tokoh dari cikal bakal raja Banjar yang mitologis. Selain menjadi orang gaib, konon ada pula tokoh zaman dulu yang menjelma menjadi naga, buaya dan konon tetap

${ }^{19}$ Hamsiah, Bidan Kampung/Tukang Pijat, Wawancara Pribadi, Banjarmasin Timur, 25 November 2017. 
hidup sampai sekarang sebagai makhluk penghuni bawah air. Alam gaib tempat orang-orang gaib hidup bermasyarakat sebenarnya ialah alam di sekeliling kita ini, Gunung Panaton dan gunung Candi dikenal sebagian masyarakat Banjar sebagai lokasi keraton masyarakat gaib, tanah rawa, pohon tertentu, antara lain Pinang Habang disekitar muara Batang Alai, sebagai lokasi perkampungan mereka.

Orang yang mempunyai keterampilan khusus atau lebih berwibawa dibanding orang lain (seniman, khususnya yang tradisional, tabib, bidan, tokoh bububan, pejabat, ulama), cenderung untuk dianggap sebagai mempunyai kekuatan gaib di dalam dirinya, mewarisi ilmu gaib dari nenek moyangnya (tutus), atau mempunyai sahabat gaib. ${ }^{20}$

Hal ini sejalan dengan pandangan dan kepercayaan bidan kampung atau tukang pijat, dari kasus-kasus yang diteliti bahwa mereka mempercayai adanya hubungan kekerabatan dengan orang gaib, yang terkadang orang gaib itu berwujud binatang buaya, dan ular dan bisa berwujud manusia. Mereka meyakini orang gaib itu bukan jin. Melainkan dari manusia yang digaibkan bisa waktu dalam kandungan bisa juga setelah lahir menghilang atau menggaib. Orang gaib ini kawin serta beranak-pinak atau berketurunan sebagaimana manusia di alam nyata ini.

Sehubungan dengan pembahasan mengenai orang gaib ini, AthThahawiyah menuturkan bahwa, di antara setan-setan itu ada yang dinamai orang-orang gaib, oleh manusia, dan sebagian manusia bisa berbicara dengan mereka. Orang-orang gaib adalah jin yang disebut "rijal" (beberapa orang).

Jika orang gaib bukan jin, tentu manusia dapat menyaksikan dan melihatnya dengan mata kepala. Minimal mereka kadang-kadang tampak kepada manusia. Orang yang mengira bahwa orang gaib itu dari manusia, maka pemikiran ini adalah suatu kekeliruan yang disebabkan karena ketidaktahuannya. ${ }^{21}$

Responden mengatakan bahwa orang gaib bukanlah jin, karena dilahirkan manusia, bisa juga dari orang yang beranak kembar. Dari anak kembar yang dilahirkan itu salah satunya hilang dalam kandungan.

${ }^{20}$ Alfani Daud, Islam Dan Masyarakat Banjar (Jakarta: Raja Grafindo Persada, 1997), 582-583.

${ }^{21}$ Umar Sulaimaan Al-Asyqr, Alam Makhluk Supernatural (Jakarta: CV. Firdaus, 1992), 105-6. 


\section{Kekerabatan dan Interaksi Simbolik Bidan Kampung dengan Urang Halus dalam Masyarakat Banjar}

Terkadang bisa dilihat oleh keluarganya, wujud penampakannya tarkadang berbentuk manusia cantik, dan terkadang berbentuk binatang seperti ular, buaya dan lainnya. Manusia tidak akan melahirkan jin sebab lain jenisnya, dan manusia hanya melahirkan manusia, walau terkadang ada yang digaibkan Allah, itulah yang disebut orang gaib.

Dalam agama Islam makhluk supernatural atau makhluk gaib itu hanya dua yang diciptakan Allah, yaitu jin dan malaikat. Sedangkan orang gaib dalam kepercayaan masyarakat Banjar itu, tidak ada ayat Al-Quran secara tegas membicarakan masalah itu. Jin diciptakan Allah SWT., dari api, sebagaimana firmannya dalam surah Al-Hijr ayat 27 dan penciptaan jin sebagaimana manusia adalah untuk mengabdi kepada Allah SWT pada surah Adz-Dzâriyat ayat 56.

Namun setelah diciptakan jin sebagaimana manusia, dia ada yang beriman kepada Allah swt., dan ada pula yang ingkar atau kafir, hal ini terdapat dalam surah Jin ayat 11,14 dan 15. Sedangkan iblis adalah dari golongan jin kapir, sebagaimana firman Allah swt. dalam surah Al-Kahfi ayat 50 .

Sehubungan iblis ini sangat jahat perbuatannya, menjerumuskan manusia, sehingga dia bisa disebut setan. Jadi setan adalah sifat jahat baik dari golongan jin ataupun dari golongan manusia, Allah berfirman dalam surah Al-An'am ayat 112.

Pembahasan adanya orang gaib ini secara tegas penulis belum menemukan. Penulis hanya menemukan dalam Al-Quran tentang makhluk gaib yaitu jin diciptakan dari api terdapat dalam Al-Quran, dan penciptaan malaikat dari cahaya ada dalam hadis.

Sedangkan pembahasan orang gaib dalam Al-Qur'an hanya ada secara tersirat menurut penulis. Hal ini terdapat dalam Al-Qur'an surah an-Nâs ayat 4-6 yang artinya:

Dari kejahatan (bisikan) syaitan yang biasa bersembunyi. Yang membisikkan (kejahatan) ke dalam dada manusia. Dari (golongan) jin dan manusia.

Penulis memahami bisikan kejahatan itu tersembunyi ke dalam dada manusia, bukan ke telinga. Dan yang membisikan itu adalah dari golongan jin dan manusia. Dari golongan jin, itulah yang disebut setan, sedang dari golongan manusia bisa saja itu yang dinamakan orang gaib. 
Istilah "orang" tentu ditujukan kepada manusia, karena bisikan itu tersembunyi dan masuk ke dalam dada (hati) manusia, bukan ke telinga. Kalau manusia biasa tentu bisikan itu ke telinga. Itulah ayat yang secara tidak tegas menurut penulis, yang bisa mendukung adanya orang gaib, kalau memang ada dalam kehidupan ini. Dan seandainya orang gaib itu dikelompokkan kepada kelompok jin penulis rasa tidak masalah juga sebab jin berarti tersembunyi, tidak kelihatan. Sedang orang gaib juga tidak kelihatan atau tersembunyi. Jadi sebenarnya tidak bertentangan antara Al-Quran dengan pengetahuan atau pengalaman masyarakat Banjar selama ini tentang adanya istilah orang gaib itu.

Dalam pembahasan antropologi tidak mengenal adanya orang gaib atau jin, yang ada hanya pembahasan mengenai jiwa yang lazim disebut "animisme". Animisme adalah suatu kepercayaan yang beranggapan bahwa segala sesuatu di alam ini mempunyai jiwa. Animisme merupakan suatu sistem kepercayaan yang berdasarkan kepada berbagai macam roh/jiwa dan makhluk halus yang berada di sekeliling tempat tinggal manusia, baik di pohon, gunung, sungai, hutan dan lainnya. ${ }^{22}$ Jiwa/roh itu dapat mendatangkan kebahagiaan dengan meraih keuntungan, baik berupa hajat terpenuhi, bisa menolong orang lain, penyakit terobati atau terhindari, Namun juga dapat mencelakakan musuh. ${ }^{23}$

Hal ini sesuai dengan kasus kedua bahwa ibunya sering membantu menjaga anak orang gaib atau makhluk gaib/ roh-roh ternyata tempatnya di pohon besar. Hanya beda istilah saja sebagian masyarakat Banjar menyebut makhluk gaib itu dengan sebutan orang gaib sementara dalam dunia antropologi disebut roh/jiwa yakni yang sering dikatakan dengan istilah animisme.

Di sisi lain pengakuan responden bahwa yang membantu mereka adalah keluarganya yang gaib, yang terkadang menampakan wujudnya dalam bentuk buaya, ular, manusia dan lainnya. Hal ini dapat dipahami sebagai "totemisme".

Kata "totem" berasal dari kata "ototeman", dialek suku Ojibwa di Amerika Utara, yang berarti kekerabatan dan kekeluargaan seperti

\footnotetext{
${ }^{22}$ Ariyono Suyono, Kamus Antropologi (Jakarta: Akademika, 1985).

${ }^{23}$ Capt. R.P. Suyono, Dunia Mistik Orang Jawa (Yogyakarta: LKiS, 2012.), 75.
} 


\section{Kekerabatan dan Interaksi Simbolik Bidan Kampung dengan Urang Halus dalam Masyarakat Banjar}

saudara. Kata tersebut sering digunakan untuk mengungkapkan adanya hubungan yang bersifat kekeluargaan antara manusia dan binatang. ${ }^{24}$

Para penganut kepercayaan totemisme meyakini bahwa mereka diturunkan dari satu leluhur totem yang mistis, atau bahwa mereka dan para anggota dari totem sejenis merupakan "saudara". Mereka menggunakan totem sebagai simbol kelompok dan menganggapnya sebagai "pelindung" kelompok secara keseluruhan. Masalah pokok dalam totemisme ialah adanya persekutuan, partisipasi dan saling menjadi bagian antara manusia dan binatang. Dari sini dapat diduga bahwa tidak jarang manusia menganggap binatang-binatang tertentu sebagai nenek moyangnya, dan manusia dapat memperoleh keselamatan, dan bantuan dari perhubungannya dengan binatang itu. ${ }^{25}$

Bidan kampung di kota Banjarmasin Timur ini, taat beragama Islam, sehingga mereka memohon perlindugan kepada Allah swt. Bukan kepada selain-Nya seperti kepada makhluk halus, buaya, ular dan lainnya. Namun mereka dapat bekerjasama dengan orang gaib yang terkadang berwujud buaya atau ular, manusia dan lainnya, dalam melakukan praktik pemijatan, atau menolong orang yang membutuhkan bantuannya.

\section{Perilaku Bidan Kampung/Tukang Pijat terhadap Makhluk Supernatural.}

Semua responden dalam kasus ini mengaku menjalin hubungan kekerabatan dengan makhluk gaib yang mereka sebut orang gaib. Hal ini dilakukan karena merasa orang gaib itu bagian dari keluarganya. Sudah tentu karena adanya rasa takut dan mengharap bantuannya, di samping sudah merupakan sebuah tradisi yang harus dijalankan, maka mereka melakukan tindakan dengan memberi hidangan atau sajian kepadanya berupa kopi pahit, kopi manis, nasi ketan, telor, pisang, bubur putih, bubur merah dll. Mereka menganggap perlakuan mereka tidak membuang-buang makanan sebab setelah itu dibacakan doa selamat, kemudian dimakan bersama keluarga.

Adanya sajian dalam antopologi adalah merupakan suatu rangkaian makanan kecil, benda-benda kecil, bunga-bunga serta barang

\footnotetext{
${ }^{24}$ Syamsuddin, "Totemisme Dan Pergeserannya."

${ }^{25}$ Ajikarsa, "Agama-Agama Primitif Totemisme," n.d., Ajiraksa.blogspot.com/2011/05/agama-agama-primitif-totemisme.html.
} 
hiasan yang semuanya disusun manurut konsep keagamaan, sehingga merupakan lambang (simbol) yang mengandung arti. Dengan persembahan sajian itu kepada tuhan, dewa, makhluk halus penghuni alam gaib lainnya, manusia bermaksud berkomunikasi dengan makhluk halus itu. ${ }^{26}$

Ada kepercayaan bahwa makhluk gaib yang mempunyai kekuatan dan kehendak, bisa merasa senang dan marah, jika ia merasa marah maka bisa membahayakan manusia. Oleh karena itu keridaannya harus dicari, diusahakan agar ia jangan marah dengan memberi makan, atau sajian memberi korban kepadanya dan mengadakan pesta-pesta khusus untuk dia berupa upacara bersaji tersebut. ${ }^{27}$ Cara beribadah kepercayaan pada masa nenek moyang dahulu selalu diindentikkan dengan diadakannya upacara-upacara bersaji, berdoa, makan bersama terhadap makanan yang telah disucikan.

Memang perilaku bidan kampung di kota Banjarmasin Timur, terhadap orang gaib, dengan cara melakukan memberi makan atau hidangan atau sajian kepadanya, pada waktu tertentu, tempat tertentu, dengan sajian tertentu pula, hal ini dalam dunia antropologi dikenal dengan sebutan upacara makan bersama dalam upacara keagamaan. Hal ini tidak bisa dikatakan membuang-buang, sebab sajian itu pada gilirannya mereka makan bersama keluarga.

\section{Simpulan}

Bidan Kampung di Kota Banjarmasin Timur punya kepercayaan adanya orang gaib, selain jin dan malaikat. Hubungan mereka dengan orang gaib ini sangat dekat, dan ada hubungan kekerabatan. Mereka yakini orang gaib inilah yang membantu mereka, sehingga punya keahlian dalam pemijatan. Orang gaib ini juga dipercayai telah mengajari mereka melalui mimpi memijat orang putih atau mimpi meluruskan benang yang kusut, yang pada gilirannya mereka memiliki keahlian dalam memijat. Orang gaib dalam pandangan mereka, bisa merubah bentuk menjadi binatang seperti buaya, ular dan lainnya. Orang gaib adalah orang atau manusia yang digaibkan Allah, bisa waktu dalam kandungan, atau setelah lahir. Mereka

${ }^{26}$ Ariyono Suyono dan Aminuddin Siregar, Kamus antropologi (Jakarta: Penerbit Akademika Pressindo, 1985), 358.

${ }^{27}$ Harun Nasution, Islam ditinjau dari berbagai aspeknya, Jilid I, 2 (Jakarta: Penerbit Universitas Indonesia, 1984). 


\section{Kekerabatan dan Interaksi Simbolik Bidan Kampung dengan Urang Halus dalam Masyarakat Banjar}

kawin mengawini dan beranak-pinak sebagaimana manusia pada umumnya.

Adapun perilaku bindan kampung terhadap orang gaib ini ialah mereka selalu menjalin hubungan kekerabatan, dengan cara memberi sesajen berupa kopi pahit, kopi manis, air putih, nasi ketan, telor, pisang, bubur merah dan bubur putih. Sasajen tersebut diletakan di tempat tertentu di dalam rumah, kemudian dibacakan doa selamat, dan dimakan bersama keluarga.

Dalam agama Islam tidak ada secara tegas tentang "orang gaib" ini, yang ada hanya jin dan malaikat. Bisa saja dalam agama Islam orang gaib itu dikelompokkan kepada jin, sebab jin artinya tersembunyi, dan orang gaib juga tersembunyi. Menurut penulis, apabila orang gaib itu benar-benar ada selain jin, maka ada saja ayat secara tersirat yang mendukung dalam Al-Quran, yaitu pada surah An-Naas ayat 4-6, yakni bisikan kejahatan itu tersembunyi ke dalam dada, bukan ke telinga, dan yang membisikan itu dari golongan jin dan manusia. Dari jin disebut setan, golongan manusia bisa saja orang gaib, sebab bisikan itu ke hati (dada) kalau manusia biasa tentu bisikan itu ke telinga, tidak ke dalam hati.

\section{Daftar Pustaka}

Adham, Ibrahim Kamal. Kupas tuntas masalah jin dan sibir. Jakarta: Darus Sunnah, 2009.

Ahmad, Maghfur. "Agama dan Psikoanalisa Sigmund Freud." RELIGLA, October 3, 2017. https://doi.org/10.28918/religia.v14i2.92.

Ajikarsa. "Agama-Agama Primitif Totemisme," n.d. Ajiraksa.blogspot.com/2011/05/agama-agama-primitiftotemisme.html.

Alfani Daud. Islam Dan Masyarakat Banjar. Jakarta: Raja Grafindo Persada, 1997.

Ariyono Suyono. Kamus Antropologi. Jakarta: Akademika, 1985.

Arni. "Kepercayaan Dan Perlakuan Masyarakat Banjar Terhadap JimatJimat Penolak Penyakit.” Jurnal Studia Insania 4, no. 1 (2016): 39_ 56. 
Bali, Wahid Abdus Salam, and Aunur Rafiq Shaleh Tamhid. Kesurupan jin dan cara pengobatannya secara Islam. Jakarta: Robbani Press, 1999.

Bali, Wahid Abdussalam, and Sarwedi Hasibuan. Ruqyah. Solo, Indonesia: PT Aqwam Media Profetika, 2011.

Capt. R.P. Suyono. Dunia Mistik Orang Jawa. Yogyakarta: LKiS, n.d.

Daradjat, Zakiah. Perbandingan Agama I. Jakarta: Bumi Aksara, 1996.

Hasan, Ridwan. "Kepercayaan Animisme Dan Dinamisme Dalam Masyarakat Islam Aceh." MIQOT: Jurnal Ilmu-Ilmu Keislaman 36, no. 2 (December 2012). https://doi.org/10.30821/miqot.v36i2.119.

Humaeni, Ayatullah. "Makna Kultural Mitos Dalam Budaya Masyarakat Banten." Antropologi Indonesia, December 18, 2013. https://doi.org/10.7454/ai.v33i3.2461.

Nasution, Harun. Islam ditinjau dari berbagai aspeknya. Jakarta: Penerbit Universitas Indonesia, 1984.

Rahmat Hidayat. Kekerabatan Dengan Makhluk Astral. Banjarmasin: IAIN Antasari Press, 2014.

Suyono, Ariyono, and Aminuddin Siregar. Kamus antropologi. Jakarta: Penerbit Akademika Pressindo, 1985.

Syamsuddin, Muh. "Totemisme Dan Pergeserannya: Studi Terhadap Tradisi Lokal Di Sendang Mandong, Klaten, Jawa Tengah.” RELIGI JURNAL STUDI AGAMA-AGAMA 13, no. 01 (2017): 96-116. https://doi.org/10.14421/rejusta.2017.1302-06.

Umar Sulaimaan Al-Asyqr. Alam Makbluk Supernatural. Jakarta: CV. Firdaus, 1992. 